\title{
Dietary habits of partly breast-fed and completely weaned infants at 9 months of age
}

\author{
Ulla Holmboe Gondolf ${ }^{1, *}$, Inge Tetens ${ }^{1}$, Kim Fleischer Michaelsen ${ }^{2}$ and Ellen Trolle ${ }^{1}$ \\ 'Department of Nutrition, National Food Institute, Technical University of Denmark, Mørkhøj Bygade 19, 2860 \\ Søborg, Copenhagen, Denmark: ${ }^{2}$ Department of Human Nutrition, University of Copenhagen, Copenhagen, \\ Denmark
}

Submitted 15 April 2011: Accepted 9 November 2011: First published online 9 December 2011

\begin{abstract}
Objective: To test whether there are differences in diet diversity between children still being partly breast-fed at 9 months and those completely weaned at the same age.

Design: Cross-sectional study.

Setting: Cross-sectional study (SKOT cohort) in the area of Copenhagen, Denmark. Subjects: Healthy term infants $(n$ 312) at 9 months of age (mean $9 \cdot 1$ (SD $0 \cdot 3)$ months).

Results: The infants partly breast-fed ( $n$ 168) at 9 months had significantly lower body weight $(P<0 \cdot 0001)$, were significantly shorter $(P=0 \cdot 0022)$ and were introduced to complementary foods significantly later $(P<0 \cdot 0001)$ than completely weaned infants ( $n$ 141) of similar age. Furthermore, they had lower intake of energy, both in absolute amount $(P<0 \cdot 0001)$ and per kilogram of body weight $(P=0 \cdot 049)$. Significantly lower intakes of most energy-yielding nutrients, in absolute amounts and as energy percentages, were seen for the partly breast-fed compared with the completely weaned infants. These differences appear to be caused primarily by differences in the type and amount of milk consumed, as the energy derived from sources other than milk was similar except for fatty spread and vegetables as a side dish. Only small differences were found for absolute intakes of foods between feeding groups, although fatty spread had significantly higher intake rates and consumption $(P=0.031)$ among partly breast-fed compared with completely weaned infants.

Conclusions: At 9 months the infants partly breast-fed did not eat a less diversified diet compared with those completely weaned at the same age. Despite later introduction to complementary foods compared with the completely weaned, their intake of foods was similar and no delay in their progression towards the family foods was noted.
\end{abstract}

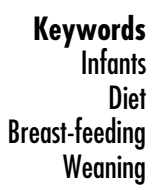

The importance of an adequate diet in infancy and early childhood has long been recognised and it has become evident that nutrition during childhood and early infancy has importance for the development of disease later in life $\mathrm{e}^{(1-3)}$.

The timing of the first introduction of complementary foods has shown to be an important factor for subsequent health. Studies have shown a protective effect of later introduction of complementary foods in relation to infancy weight gain ${ }^{(4)}$, adult overweight ${ }^{(5)}$ and respiratory illness during childhood ${ }^{(6)}$. A longer duration of breastfeeding is associated with a delayed introduction of complementary foods ${ }^{(4,7,8)}$ and results from a large cohort study showed an interaction between breast-feeding and introduction of complementary foods, suggesting that the combination of short periods of breast-feeding and early introduction of complementary foods may contribute to increased infancy weight gain ${ }^{(4)}$. The effect of early introduction of complementary foods on overweight later in life is not known, but it has been suggested that individuals introduced early to complementary foods are more susceptible to an obesogenic environment, involving both physiological and psychological factors ${ }^{(5)}$.

Several studies have reported differences in food intake between infants being partly breast-fed and those completely weaned in the second half of infancy, where foods and drinks become an increasing part of the $\operatorname{diet}^{(9-13)}$. Whether this difference is caused by delay in the progression towards spoon feeding due to later introduction to complementary foods is uncertain, but of interest for future investigations on breast-feeding and later health outcomes. Moreover, this could be beneficial for counselling 
of mothers and fathers in healthy infant feeding practices. For this reason the aim of the present study was to test whether there are differences in diet diversity between children still being partly breast-fed at 9 months and those completely weaned at the same age.

\section{Materials and methods}

Data for the present study were obtained from infants seen at the first examination of the SKOT cohort, an ongoing prospective cohort which has the overall aim to describe how complementary feeding influences growth, development and risk factors for later disease. The infants were examined at age 9 months \pm 2 weeks.

A random sample of 9-month-old infants living in Copenhagen and Frederiksberg was established through the National Danish Civil Registry. The sample included infants born from April 2007 to May 2008. An invitation was posted to 2211 families, 4 to 7 weeks before the infants turned 9 months of age. The inclusion criteria were singleton infants born at $\geq 37$ weeks of gestation and without diseases expected to affect growth or food intake. Written consent to participate was obtained from parents. An interview on diet, growth and health of the infant was performed, and instruction on food recording was given. The age of the infant at which full and partial breast-feeding stopped was recorded, and for infants still being breast-fed information on the daily frequency the infant was breast-fed a meal or part of a meal, according to the parent, was obtained. The parent was told that a breast-feed for comfort should not be counted. Less than once per day was coded as zero. Full breast-feeding was defined as only receiving breast milk, water, vitamins and minerals. The study protocol was approved by The Committees on Biomedical Research Ethics for the Capital Region of Denmark (H-KF-2007-0003).

At the examination nude weight to the nearest $1 \mathrm{~g}$ was measured for all infants using a digital paediatric scale (Saratorius IP 65; Bie \& Berntsen AS, Herlev, Denmark). Recumbent length was measured using a digital measuring board (Force Technology, Brondby, Denmark) and recorded to the nearest $0.5 \mathrm{~cm}$. All measurements were performed by four well-trained observers.

The diet was recorded for seven consecutive days using a validated method consisting of pre-coded booklets accompanied by a booklet with twelve food photograph series ${ }^{(14)}$. The pre-coded food record was developed specifically for children between 6 months and 4 years of age and the booklets were divided into different parts corresponding to breakfast, lunch, dinner and in-between meals. The quantities were estimated from standard portion sizes, household measures or from the twelve food photograph series, depending on the specific food or drink. At the end of each meal and each group of food or drink, blank fields were present for the parents to use if appropriate. If the child attended day care the food and drinks were recorded in household measures by the day care staff on a sheet, and then transferred to the pre-coded food record by the parents. In the study, the pre-coded food booklets were checked for completeness after the registration period, so any inappropriate responses could be clarified immediately.

All intakes of energy, nutrients and food items recorded in the pre-coded food record were calculated for each individual using the software system GIES version 1.000d, developed at the National Food Institute, Technical University of Denmark (Søborg, Denmark), and the Danish Food Composition Databank version 7 (National Food Institute, Technical University of Denmark; http://www. Foodcomp.dk). The intake model in GIES operates with three separate data layers: the recorded food intake, recipes and food composition data. The Danish Food Composition Databank and the recipes were amended to include products and recipes common for infants and young children.

To estimate the quantity of breast milk consumed, information on the frequency of feeding was used combined with data on the volume of breast milk per feed from Dewey et al. ${ }^{(15)}$. If the child received breast milk $\geq 6$ times/d, the assigned volume was $130 \mathrm{ml} / \mathrm{feed}$; with $3-5 \mathrm{feeds} / \mathrm{d}$, the assigned volume was $89 \mathrm{ml} / \mathrm{feed}$; and with $<3$ feeds/d, the volume assigned was $53 \mathrm{ml} /$ feed. The nutritional content of breast milk was calculated according to published values ${ }^{(16,17)}$.

Estimation of the degree of possible over- and underreporting was done by comparing each infant's daily energy intake with his/her likely energy requirement, as described by Conn et al. ${ }^{(18)}$. In brief, each infant's energy requirement was calculated according to values obtained by the doubly labelled water method for 9-month-old infants ${ }^{(19)}$. Subsequently, $95 \%$ confidence limits around the total energy expenditure value were added ${ }^{(20)}$ and the range was used as plausible intake.

Anthropometric measurements were entered into the software program WHO Anthro 2005 (WHO, Geneva, Switzerland; http://www.who.int/childgrowth/software/en/).

Intakes of energy-yielding nutrients were presented as means and standard deviations, and the $t$ test was used to test if the intake differed between feeding groups. Because of the skewed distribution, added sugars were presented as median values and the Mann-Whitney $U$ test was used to test if the intake differed between the feeding groups. Estimated intakes of foods and food groups are presented as medians, 25th and 75th percentile $\left(\mathrm{P}_{25}\right.$ and $\mathrm{P}_{75}$ ), and comparison of the groups partly breast-fed and completely weaned was done with the Mann-Whitney $U$ test. The two feeding groups were also compared adjusting for weight of the infant, mother's age, mother's education and number of persons in the household using the general linear model. Comparisons between categorical values were made using the $\chi^{2}$ test. All $P$ values are two-sided with a level of significance of $P<0.05$. 
Data were analysed with the SAS for Windows statistical software package version 9.1 (SAS Institute Inc., Cary, NC, USA).

\section{Results}

Three hundred and twelve infants participated and were examined. Of these, two were excluded because of too many missing recordings days $(>2 \mathrm{~d})$ and one due to unrealistically high intakes of energy and fat. Thus the final study sample included 309 infants with a mean age at examination of $9 \cdot 1(\mathrm{SD} 0 \cdot 3)$ months. Almost all infants (99\%) had received breast milk at some time and 141 were still partly breast-fed (46\%) at 9 months. The median $\left(\mathrm{P}_{25}, \mathrm{P}_{75}\right)$ duration of exclusive breast-feeding was $4 \cdot 2(2 \cdot 5,5 \cdot 1)$ months. The majority of the infants were Caucasian and eleven ( $4 \%$ ) had mixed Caucasian/ non-Caucasian parents. Selected characteristics of all infants and their mothers, and according to partly breastfed and completely weaned feeding groups, are presented in Table 1. Mothers of partly breast-fed infants were more likely to be less than 35 years of age and to be higher educated than mothers of completely weaned infants. No differences between the two groups were seen for number of persons in the household, household income or birth weight of the infant. The partly breast-fed infants were significantly lighter, shorter, had lower BMI Z-score and were introduced to complementary foods later than completely weaned infants (Fig. 1).

In absolute terms, partly breast-fed infants had lower energy intake than completely weaned infants (Table 2). When analysed per kilogram of body weight these differences were reduced considerably, only just reaching the significance level. For absolute intakes of protein and carbohydrate, partly breast-fed infants had lower intakes than the completely weaned infants; however, no difference was found for fat and added sugars. Comparing nutrient densities, the percentage of energy provided by protein and carbohydrate was lower for partly breast-fed infants than for completely weaned infants, but higher for fat. Despite differences between the two groups all overall mean intakes for the energy-yielding nutrients were within the recommendations for this age group ${ }^{(21)}$.

Table 1 Characteristics* of all mothers and infants surveyed and according to feeding group: healthy term infants at 9 months of age, SKOT cohort, Copenhagen, Denmark

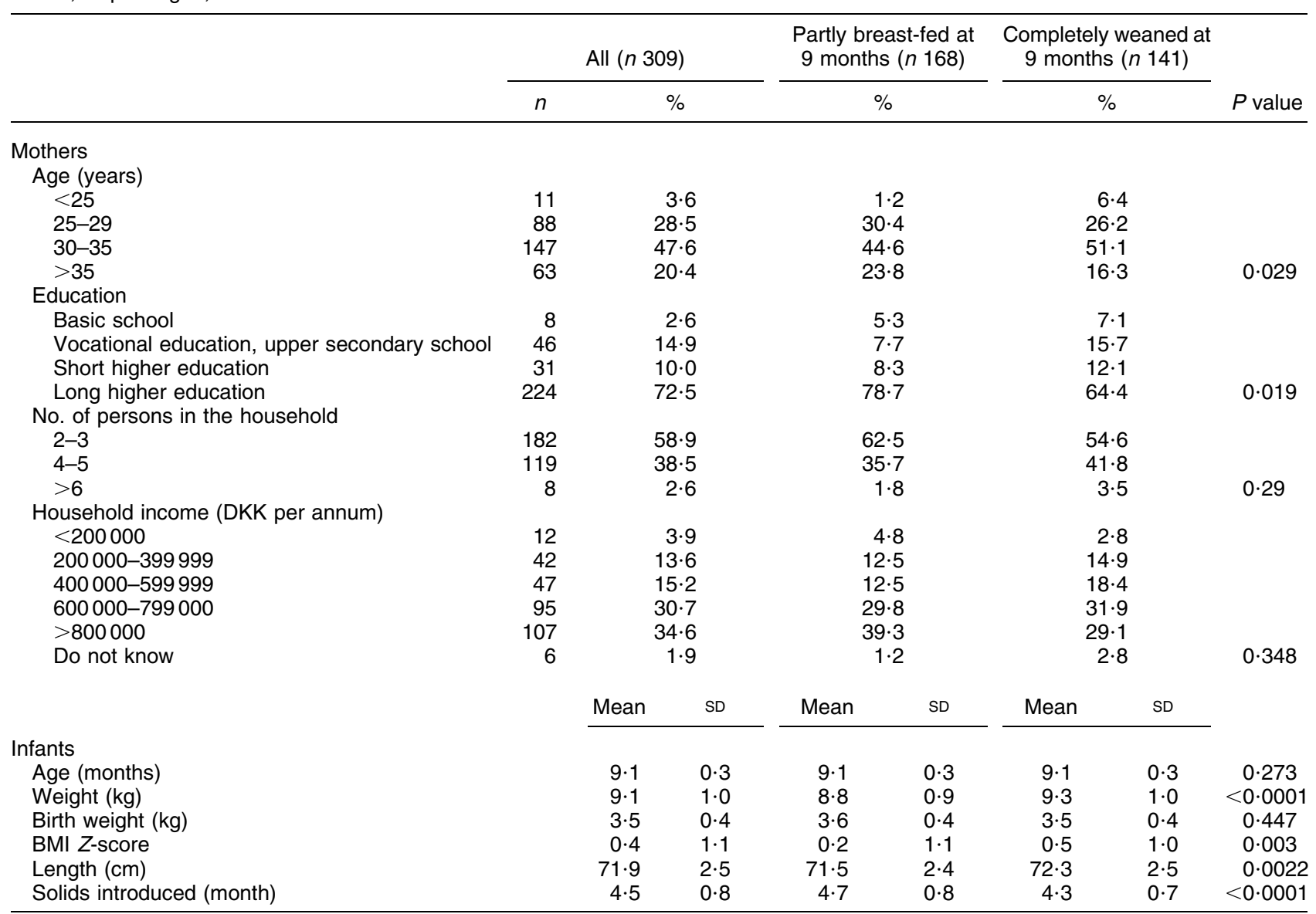

DKK, Danish krone.

*Percentages for categorical variables and means and standard deviations for continuous variables. 
Comparison of the proportions of partly breast-fed and completely weaned infants consuming selected foods and food groups showed that partly breast-fed infants were, as expected, less likely to drink formula $(P<0 \cdot 0001)$ and if they did so the median daily intake was much lower (Table 3). Also gruel was consumed less frequently $(P<0 \cdot 0001)$ and in much smaller amounts by partly breast-fed infants compared with completely weaned $(P<0 \cdot 0001$; data not shown). Although similar proportions of partly breast-fed and completely weaned infants drank cow's milk $(P=0 \cdot 676)$, smaller amounts by the former were recorded. Considering foods, similar proportions of the partly breast-fed and completely weaned infants consumed porridge $(P=0 \cdot 279)$, fruit purée and vegetable purée $(P=0 \cdot 146$ and $P=0 \cdot 337$, respectively), milk products $(P=0 \cdot 215)$, bread $(P=0 \cdot 942)$, vegetables/vegetable products $(P=0 \cdot 667)$, vegetables as a

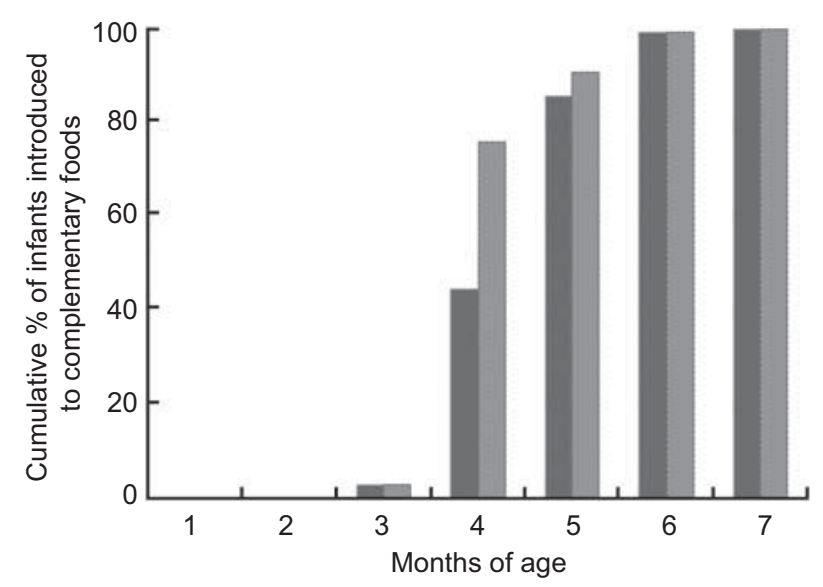

Fig. 1 Cumulative percentage of infants introduced to complementary foods per month ( $\square$, among those who were partly breast-fed at 9 months; $\square$, among those who were completely weaned infants at 9 months): healthy term infants ( $n$ 309) at 9 months of age, SKOT cohort, Copenhagen, Denmark side dish $(P=0 \cdot 067)$, fruit/fruit products $(P=0 \cdot 867)$, fruit in pieces $(P=0 \cdot 222)$, meat $/$ meat products $(P=0 \cdot 092)$, fish/fish products $(P=0 \cdot 200)$ and potatoes/rice/pasta $(P=0 \cdot 427)$. However, partly breast-fed infants were more likely to consume fatty spread $(P=0 \cdot 039)$ and less likely to consume cakes/ice cream/sweets $(P=0 \cdot 024)$. In absolute terms, partly breast-fed infants consumed less industrially produced fruit purée $(P=0.033)$ and cakes/ice cream/sweets $(P=0.005)$ and more fatty spread $(P=0.023)$ and vegetables as a side dish $(P=0 \cdot 013)$ than the completely weaned infants. Adjusting for the weight of the infant, mother's age, mother's education and number of persons in the household, the only differences were that vegetables and cakes/ice cream/sweets lost significance, but industrial porridge $(P=0.026)$ and milk products $(P=0.044)$ became significant with the partly breast-fed eating less than the completely weaned (Table 3).

Unadjusted values for the contribution of energy from selected foods and food groups to total energy (covering $95 \%$ of the energy intake) showed that formula contributed less to the daily energy intake for the partly breast-fed infants compared with the completely weaned $(P<0 \cdot 001)$. The same was seen for gruel $(P<0 \cdot 001)$. Considering the contribution of energy from food sources, the partly breast-fed infants received more energy from vegetables as a side dish $(P=0.004)$ and fatty spread $(P=0 \cdot 0005)$ and less from cakes/ice cream/sweets $(P=0 \cdot 009)$ compared with the completely weaned infants. Adjusting for the same covariates as above, the only difference was that cakes/ice cream/sweets lost significance (Table 4).

Regarding over- and under-reporters we found that about $11 \%$ of the infants in both groups were possible over-reporters and $3 \%$ and $0 \%$ were possible underreporters in the partly breast-fed group and the completely weaned group, respectively.

Table 2 Daily macronutrient intakes (inclusive of estimated breast milk intake) of all infants surveyed and according to feeding group: healthy term infants at 9 months of age, SKOT cohort, Copenhagen, Denmark

\begin{tabular}{|c|c|c|c|c|c|c|c|c|}
\hline & \multicolumn{2}{|c|}{ All (n 309) } & \multicolumn{2}{|c|}{$\begin{array}{l}\text { Partly breast-fed at } \\
9 \text { months ( } n 168)\end{array}$} & \multicolumn{2}{|c|}{$\begin{array}{l}\text { Completely weaned at } \\
9 \text { months }(n 141)\end{array}$} & \multirow{2}{*}{$\begin{array}{l}\text { Recommended } \\
\text { intake* }\end{array}$} & \multirow[b]{2}{*}{$P$ valuet } \\
\hline & Mean & SD & Mean & SD & Mean & SD & & \\
\hline Energy (kJ) & 3476 & 908 & 3284 & 937 & 3708 & 816 & & $<0.0001$ \\
\hline Energy (kJ/kg) & 387 & 107 & 377 & 116 & 400 & 93 & 355 & 0.049 \\
\hline Protein $(g / d)$ & $24 \cdot 9$ & $8 \cdot 4$ & $22 \cdot 1$ & $7 \cdot 8$ & $28 \cdot 3$ & $7 \cdot 9$ & & $<0.0001$ \\
\hline Protein (\%E) & $12 \cdot 1$ & $2 \cdot 2$ & $11 \cdot 4$ & $2 \cdot 4$ & $12 \cdot 9$ & $1 \cdot 6$ & $7-15$ & $<0.0001$ \\
\hline Total CHO $(\mathrm{g} / \mathrm{d})$ & $105 \cdot 5$ & $28 \cdot 2$ & $97 \cdot 5$ & 28.9 & $115 \cdot 2$ & $24 \cdot 1$ & & $<0.0001$ \\
\hline Total CHO (\%E) & $51 \cdot 9$ & $6 \cdot 2$ & $50 \cdot 8$ & $6 \cdot 4$ & $53 \cdot 2$ & $5 \cdot 8$ & $45-60$ & 0.0006 \\
\hline Added sugars $(\mathrm{g} / \mathrm{d}) \ddagger$ & $2 \cdot 5$ & $0.9,5 \cdot 1$ & $2 \cdot 0$ & $0 \cdot 6,4 \cdot 4$ & $2 \cdot 9$ & $1 \cdot 4,6 \cdot 5$ & & 0.002 \\
\hline Added sugars (\%E) & $2 \cdot 2$ & $2 \cdot 4$ & $2 \cdot 2$ & $2 \cdot 7$ & $2 \cdot 1$ & $2 \cdot 0$ & $\operatorname{Max} 10$ & 0.764 \\
\hline Total fat $(g / d)$ & $35 \cdot 8$ & $11 \cdot 6$ & $35 \cdot 3$ & $12 \cdot 1$ & $36 \cdot 4$ & 11 & & 0.387 \\
\hline Total fat (\%E) & $37 \cdot 9$ & $6 \cdot 0$ & $39 \cdot 5$ & $6 \cdot 0$ & $36 \cdot 0$ & $5 \cdot 4$ & $30-45$ & $<0.0001$ \\
\hline
\end{tabular}

$\% \mathrm{E}$, percentage of energy intake; $\mathrm{CHO}$, carbohydrate.

${ }^{*}$ Nordic Council of Ministers, $2004^{(21)}$.

tComparing breast-feeding groups by the Student $t$ test or the Mann-Whitney $U$ test (added sugars).

¥Median value and 25th, 75th percentiles because of the skewed distribution. 
Table 3 Daily intakes $(\mathrm{g} / \mathrm{d})$ of selected foods and drinks and percentages of consumers among all infants surveyed and according to feeding group: healthy term infants at 9 months of age, SKOT cohort, Copenhagen, Denmark

\begin{tabular}{|c|c|c|c|c|c|c|c|c|c|c|}
\hline \multirow[b]{2}{*}{ Food group } & \multicolumn{2}{|c|}{ All $(n 309)$} & \multicolumn{3}{|c|}{ Partly breast-fed at 9 months ( $n$ 168) } & \multicolumn{3}{|c|}{ Completely weaned at 9 months $(n 141)$} & \multirow[b]{2}{*}{$\begin{array}{c}\text { Unadjusted } \\
P \text { value }\end{array}$} & \multirow[b]{2}{*}{$\begin{array}{l}\text { Adjusted } \\
P \text { value* }\end{array}$} \\
\hline & Median & $\mathrm{P}_{25}, \mathrm{P}_{75}$ & $\begin{array}{c}\% \\
\text { consuming }\end{array}$ & Median & $\mathrm{P}_{25}, \mathrm{P}_{75}$ & $\begin{array}{c}\% \\
\text { consuming }\end{array}$ & Median & $\mathrm{P}_{25}, \mathrm{P}_{75}$ & & \\
\hline \multicolumn{11}{|l|}{ Drinks } \\
\hline Breast milk & 0 & 0,80 & 100 & 80 & 80,355 & 0 & - & - & $<0.0001$ & $<0.0001$ \\
\hline Formula & 126 & 0,387 & 48 & 0 & 0,114 & 92 & 377 & 231,477 & $<0.0001$ & $<0.0001$ \\
\hline Follow-on formula & 0 & 0,0 & 8 & 0 & 0,0 & 28 & 0 & 0,36 & $<0.0001$ & $<0.0001$ \\
\hline Cow's milk (drinking) & 43 & 1,118 & 71 & 36 & 0,109 & 79 & 46 & 5,118 & $<0.0001$ & $<0.0001$ \\
\hline Juice/squash/soft drinks & 0 & 0,0 & 13 & 0 & 0,0 & 20 & 0 & 0,0 & 0.060 & 0.748 \\
\hline \multicolumn{11}{|l|}{ Foods } \\
\hline Porridge & & & 99 & & & 99 & & & & \\
\hline Home-made & 107 & 43,171 & 93 & 105 & 47,170 & 89 & 107 & 43,171 & 0.793 & 0.936 \\
\hline Industrial & 4 & 0,50 & 48 & 0 & 0,43 & 53 & 11 & 0,64 & 0.217 & 0.026 \\
\hline Fruit purée & & & 74 & & & 82 & & & & \\
\hline Home-made & 7 & 0,32 & 55 & 4.5 & 0,29 & 58 & $7 \cdot 1$ & 0,36 & 0.497 & 0.729 \\
\hline Industrial & 4 & 0,29 & 47 & 0 & 0,21 & 55 & 7 & 0,36 & 0.033 & 0.0013 \\
\hline Vegetable purée & & & 82 & & & 81 & & & & \\
\hline Home-made & 34 & 0,100 & 71 & 33 & 0,98 & 74 & 36 & 0,100 & 0.918 & 0.983 \\
\hline Industrial & 0 & 0,21 & 35 & 0 & 0,17 & 40 & 0 & 0,25 & 0.246 & 0.267 \\
\hline Milk productst & 3 & 0,39 & 54 & 4 & 0,31 & 51 & 0 & 0,50 & 0.952 & 0.044 \\
\hline Bread & 24 & 13,39 & 96 & 23 & 11,39 & 98 & 26 & 13,39 & 0.560 & 0.074 \\
\hline Fatty spread & 2 & 1,4 & 85 & 3 & 1,4 & 81 & 2 & 0,4 & 0.023 & 0.031 \\
\hline Vegetables/vegetable products & 34 & 18,56 & 99 & 35 & 18,55 & 99 & 33 & 19,57 & 0.743 & 0.918 \\
\hline Vegetables as a side dish & 10 & 1,22 & 82 & 12 & 3,27 & 79 & 8 & 1,18 & 0.013 & $0 \cdot 125$ \\
\hline Fruit/fruit products & 84 & 49,121 & 100 & 83 & 49,121 & 100 & 87 & 49,122 & 0.865 & 0.816 \\
\hline Fruit in pieces & 58 & 29,90 & 98 & 57 & 28,89 & 94 & 58 & 30,91 & 0.786 & 0.820 \\
\hline Meat $/$ meat products & 13 & 6,24 & 96 & 12 & 5,22 & 99 & 16 & 7,26 & 0.066 & $0 \cdot 163$ \\
\hline Fish/fish products & 5 & 1,10 & 88 & 5 & 2,10 & 88 & 5 & 2,11 & 0.476 & 0.443 \\
\hline Potatoes/rice/pasta & 6 & 0,22 & 70 & 6 & 0,19 & 75 & 7 & 0,23 & 0.399 & 0.888 \\
\hline Cakes/ice cream/sweets & 0 & 0,2 & 36 & 0 & 0,1 & 50 & 0 & 0,3 & 0.005 & $0 \cdot 162$ \\
\hline
\end{tabular}

$P_{25}, 25$ th percentile; $P_{75}, 75$ th percentile.

${ }^{*}$ Comparing intakes from breast-feeding groups by general linear models adjusted for weight of the infant, mother's age, mother's education and number of persons in the household. tNot potable milk products, including yoghurt and milk on cereals. 
Table 4 Contribution (\%) of selected foods and food groups to total energy intake among all infants surveyed and according to feeding group: healthy term infants at 9 months of age, SKOT cohort, Copenhagen, Denmark

\begin{tabular}{|c|c|c|c|c|c|c|c|c|}
\hline \multirow[b]{2}{*}{ Food group } & \multicolumn{2}{|c|}{ All $(n$ 309) } & \multicolumn{2}{|c|}{$\begin{array}{l}\text { Partly breast-fed at } \\
9 \text { months }(n \text { 168) }\end{array}$} & \multicolumn{2}{|c|}{$\begin{array}{l}\text { Completely weaned at } \\
9 \text { months }(n 141)\end{array}$} & \multirow[b]{2}{*}{$\begin{array}{l}\text { Unadjusted } \\
P \text { value }\end{array}$} & \multirow[b]{2}{*}{$\begin{array}{l}\text { Adjusted } \\
P \text { value }\end{array}$} \\
\hline & Median & $P_{25}, P_{75}$ & Median & $P_{25}, P_{75}$ & Median & $P_{25}, P_{75}$ & & \\
\hline \multicolumn{9}{|l|}{ Drinks } \\
\hline Formula & $10 \cdot 2$ & $0,28 \cdot 7$ & 0 & $0,8 \cdot 8$ & $28 \cdot 6$ & $15 \cdot 5,38 \cdot 3$ & $<0.0001$ & $<0.0001$ \\
\hline Gruel & 0 & 0,0 & 0 & 0,0 & 0 & $0,2 \cdot 6$ & $<0.0001$ & 0.0001 \\
\hline Cow's milk & $1 \cdot 2$ & $0,3 \cdot 1$ & $1 \cdot 1$ & $0,3 \cdot 1$ & $1 \cdot 3$ & $0 \cdot 1,3 \cdot 2$ & 0.476 & 0.907 \\
\hline Juice/squash/soft drinks & 0 & 0,0 & 0 & 0,0 & 0 & 0,0 & 0.076 & 0.077 \\
\hline \multicolumn{9}{|l|}{ Foods } \\
\hline Vegetable purée & 4.8 & $1 \cdot 1,11 \cdot 2$ & 4.9 & $1 \cdot 0,11 \cdot 3$ & $4 \cdot 7$ & $1 \cdot 3,11 \cdot 1$ & 0.817 & 0.881 \\
\hline Milk productst & 0.4 & $0,3.7$ & 0.5 & $0,3 \cdot 3$ & 0 & $0,4.5$ & 0.987 & $0 \cdot 262$ \\
\hline Bread & 7.5 & $4 \cdot 3,11 \cdot 1$ & $7 \cdot 7$ & $4 \cdot 1,12 \cdot 0$ & $7 \cdot 1$ & $4 \cdot 4,10 \cdot 1$ & $0 \cdot 223$ & $0 \cdot 104$ \\
\hline Fatty spread & 1.8 & $0.5,3.5$ & $2 \cdot 4$ & $0.9,4.1$ & 1.5 & $0 \cdot 3,3 \cdot 0$ & 0.0005 & 0.0004 \\
\hline Vegetables as a side dish & 0.6 & $0 \cdot 1,2 \cdot 2$ & $1 \cdot 1$ & $0 \cdot 2,2 \cdot 8$ & 0.4 & $0 \cdot 1,1 \cdot 5$ & 0.0004 & 0.0003 \\
\hline Fruit in pieces & $5 \cdot 3$ & $2 \cdot 8,7 \cdot 7$ & $5 \cdot 5$ & $3 \cdot 0,8 \cdot 4$ & $4 \cdot 7$ & $2 \cdot 5,7 \cdot 2$ & $0 \cdot 225$ & 0.0751 \\
\hline Meat/meat products & 3.8 & $1 \cdot 7,6 \cdot 2$ & 3.5 & $1 \cdot 5,6 \cdot 0$ & $4 \cdot 0$ & $1 \cdot 8,6 \cdot 3$ & 0.298 & 0.517 \\
\hline Fish/fish products & 0.8 & $0 \cdot 2,1 \cdot 7$ & 0.8 & $0 \cdot 2,1 \cdot 6$ & 0.7 & $0 \cdot 2,1 \cdot 8$ & 0.897 & 0.536 \\
\hline Potatoes/rice/ pasta & $1 \cdot 0$ & $0,3 \cdot 0$ & $1 \cdot 0$ & $0,3 \cdot 0$ & 0.9 & $0,3 \cdot 1$ & 0.782 & $0 \cdot 193$ \\
\hline
\end{tabular}

$P_{25}$, 25th percentile; $P_{75}$, 75th percentile.

"Comparing breast-feeding groups by general linear models adjusted for weight of the infant, mother's age, mother's education and number of persons in the household.

tNot potable milk products, including yoghurt and milk on cereals. 


\section{Discussion}

The present results showed that infants partly breast-fed at 9 months do not eat less diversified diets compared with those completely weaned at the same age, despite later introduction to complementary foods. They had lower intake of energy, both in absolute amounts and per kilogram of body weight, even though the significance decreased when adjusting for body weight. Lower intakes of most energy-yielding nutrients were seen for the partly breast-fed compared with the completely weaned infants. These differences appear to be caused primarily by differences in the type and amount of milk consumed, as the energy derived from sources other than milk was similar, except for fatty spread and vegetables as a side dish (Table 4). This result is in agreement with findings from studies of 9-month-old infants from both the USA and Australia $^{(9,18)}$. However, the present study found only small differences for intakes of foods between groups, although fatty spread showed significantly higher intake rates and consumption among partly breast-fed compared with completely weaned infants. A higher intake of fatty spread was also recorded for partly breast-fed infants at 12 months of age compared with non-breast-fed infants at the same age in a study by Lande et al. ${ }^{(10)}$. It is possible that mothers of the partly breast-fed infants in the present study were more focused on including fatty spread in generous amounts in their infants' diet, due to concern about their infants' energy intake, as these infants generally were leaner than the completely weaned infants. The absolute fat intake was similar in the present study for the two groups of infants, resulting in a significantly higher contribution of fat to total energy for the partly breast-fed infants. This difference may partly be due to a significantly higher contribution of fatty spread to total energy for the partly breast-fed infants. Fat contributed on average $40 \%$ of dietary energy for infants who were still breast-fed and $36 \%$ of dietary energy for infants who were not. These values are well within the Nordic Nutrient Recommendations 2004 for this age group (30-45\% of energy), but are considerably higher than figures reported from the Copenhagen Cohort Study, in which the percentage of energy from fat for 9-month-old infants was $32 \%$ and $31 \%$ respectively for partially breastfed $v$. not breast-fed infants ${ }^{(11,21)}$. The Copenhagen Cohort Study raised concerns about inadequate fat intake in infants, which was supported by several international studies $^{(22,23)}$. Subsequently more focus in dietary guidelines in Denmark has been placed on the importance of infants receiving fat in adequate amounts and our results may reflect this effort.

Regarding drinks, the present study did not find any difference in intake of sugar-sweetened drinks (juice/ squash/soft drinks) between the two feeding groups. In contrast, several studies found a significantly lower intake of sugar-sweetened drinks among completely weaned infants compared with infants being partially breast-fed ${ }^{(10,11,13)}$.

The partly breast-fed infants had considerably lower intakes of formula and cow's milk compared with the completely weaned, which is reflected in their lower protein intake. In contrast to most countries, in Denmark it is recommended that cow's milk be introduced gradually: from the age of 9 months it can gradually become the main milk, while very small amounts can be given from the age of 6 months ${ }^{(24)}$. Many countries, including the USA and the UK, do not recommend that cow's milk is used as the main milk before the age of 12 months ${ }^{(25,26)}$. The main reason for delaying the introduction of cow's milk in the diet is to prevent the development of $\mathrm{Fe}$ deficiency and to avoid high protein intake, as the Fe content of cow's milk is very low, while high in protein. However, the protein intake of the infants in both feeding groups in the present study and in the other Danish study (the Copenhagen Cohort Study) is comparable with that of infants at the same age in other countries ${ }^{(11,12,18)}$.

In the present study the infants were introduced to complementary foods at a mean age of $4 \cdot 7$ ( $\mathrm{SD} 0 \cdot 8)$ months and 4.3 (SD 0.7$)$ months, respectively, for partially breast-fed infants and completely weaned infants. Of these only $3 \%$ from each group were introduced before 4 months (Fig. 1). This is in accordance with the Danish recommendations recommending exclusive breast-feeding up until 6 months; however, complementary foods may be introduced from 4 months of age to support optimal growth and development ${ }^{(24)}$. The mean introduction times in the present study are in remarkable contrast to those found for infants from other industrialized countries. An analysis of five European countries found that $37 \%$ of formula-fed infants and $17 \%$ of breast-fed infants were introduced to complementary foods at 4 completed months ${ }^{(27)}$, despite the fact that in 2001 WHO changed the recommendation for introducing complementary foods from $4-6$ months to 6 months ${ }^{(28)}$. The Committee on Nutrition of the European Society for Paediatric Gastroenterology, Hepatology and Nutrition concluded likewise in 2008 that exclusive or full breast-feeding for about 6 months is a desirable goal ${ }^{(29)}$.

In the present study breast milk intake was estimated from frequency of feeding, which may be a rather crude estimate, not taking into account the duration of feeding and the variation in milk composition during a feed. Ideally, test weighing of milk intake, information on the duration of each feed and milk samples from each mother should have been collected. However, this requires extreme effort by the participants and was not a possibility in our study. The methods used for estimation of breast milk intake in the present study are comparable to those used in other studies ${ }^{(12,18)}$. Still, a potential small underestimation of the breast milk intake may be present. The mothers were asked about the frequency they breast-fed their infants a meal, and those who did 
not breast-feed whole meals were coded as zero and no energy from breast milk was added to their total energy intake. The mean energy intake of the breast-fed infants in the present study was $3284 \mathrm{~kJ} / \mathrm{d}$, which is similar to earlier reported intakes from breast-fed infants at the same age ${ }^{(12,18,22)}$. However, slightly lower intakes have been reported in studies where test weighing of the breast milk intake was performed, but in these studies the fat energy percentage was correspondingly lower ${ }^{(11,22)}$.

One limitation of the present study is the presence of possible over- and under-reporters. However, by estimating the degree of possible over- and under-reporters we found that about $11 \%$ of the infants in both groups were possible over-reporters and only $3 \%$ and $0 \%$ were possible under-reporters in the partly breast-fed group and the completely weaned group, respectively. In comparison, Conn et al. ${ }^{(18)}$ found that $32 \%$ were likely to be over-reporting and $<1 \%$ under-reporting, using the same method. We chose not to exclude these possible over- and under-reporters as intakes in this age group may vary a lot and most infants classified as possible overreporters were just above the calculated limit.

The present study consists of infants from the Copenhagen area. The parents were well educated, motivated and may have been more health conscious than the majority, resulting in a sample that may not have been representative. This might increase compliance with advice on weaning, resulting in a more homogeneous sample than expected. It is conceivable that a larger deviation between the two feeding groups with regard to introduction time of complementary foods could have resulted in more significant dietary differences than noted in our study.

\section{Conclusion}

The present study showed in a Danish cohort of 9-monthold infants that partly breast-fed infants did not eat less diversified diets compared with those completely weaned at the same age. Despite later introduction to complementary foods than for those completely weaned, their intake of foods was similar and no delay in their progression towards the family foods was noted.

\section{Acknowledgements}

The study was supported by grants from the Danish Directorate for Food, Fisheries and Agri Business. The authors have no conflict of interests. U.H.G. was the primary writer of the paper. K.F.M. initiated the cohort study. All authors commented on drafts. The authors gratefully acknowledge the contribution of all of the families and children who participated in the study and Tue Christensen for help with the nutritional calculations.

\section{References}

1. Berenson GS (2002) Childhood risk factors predict adult risk associated with subclinical cardiovascular disease. The Bogalusa Heart Study. Am J Cardiol 90, 3L-7L.

2. Caballero B (2001) Early nutrition and risk of disease in the adult. Public Health Nutr 4, 1335-1336.

3. Guo SS, Wu W, Chumlea WC et al. (2002) Predicting overweight and obesity in adulthood from body mass index values in childhood and adolescence. Am J Clin Nutr 76, 653-658.

4. Baker JL, Michaelsen KF, Rasmussen KM et al. (2004) Maternal prepregnant body mass index, duration of breastfeeding, and timing of complementary food introduction are associated with infant weight gain. Am J Clin Nutr 80, 1579-1588.

5. Schack-Nielsen L, Sorensen TI, Mortensen EL et al. (2010) Late introduction of complementary feeding, rather than duration of breastfeeding, may protect against adult overweight. Am J Clin Nutr 91, 619-627.

6. Wilson AC, Forsyth JS, Greene SA et al. (1998) Relation of infant diet to childhood health: seven year follow up of cohort of children in Dundee infant feeding study. BMJ 316, 21-25.

7. Burdette HL, Whitaker RC, Hall WC et al. (2006) Breastfeeding, introduction of complementary foods, and adiposity at 5 y of age. Am J Clin Nutr 83, 550-558.

8. Kramer MS (1981) Do breast-feeding and delayed introduction of solid foods protect against subsequent obesity? J Pediatr 98, 883-887.

9. Heinig MJ, Nommsen LA, Peerson JM et al. (1993) Energy and protein intakes of breast-fed and formula-fed infants during the first year of life and their association with growth velocity: the DARLING Study. Am J Clin Nutr $\mathbf{5 8 ,}$ $152-161$

10. Lande B, Andersen LF, Veierod MB et al. (2004) Breastfeeding at 12 months of age and dietary habits among breast-fed and non-breast-fed infants. Public Health Nutr 7 , 495-503.

11. Michaelsen KF (1997) Nutrition and growth during infancy. The Copenhagen Cohort Study. Acta Paediatr Suppl 420, $1-36$.

12. Noble S \& Emmett P (2001) Food and nutrient intake in a cohort of 8-month-old infants in the south-west of England in 1993. Eur J Clin Nutr 55, 698-707.

13. North K, Emmett P, Noble S et al. (2010) Types of drinks consumed by infants at 4 and 8 months of age: sociodemographic variations. J Hum Nutr Diet 13, 71-82.

14. Gondolf UH, Tetens I, Hills A et al. (2011) Validation of a pre-coded food record for infants and young children. Eur J Clin Nutr (Epublication ahead of print version).

15. Dewey KG, Finley DA \& Lonnerdal B (1984) Breast milk volume and composition during late lactation (7-20 months). J Pediatr Gastroenterol Nutr 3, 713-720.

16. Michaelsen KF, Larsen PS, Thomsen BL et al. (1994) The Copenhagen Cohort Study on Infant Nutrition and Growth: breast-milk intake, human milk macronutrient content, and influencing factors. Am J Clin Nutr 59, 600-611.

17. Department of Health and Social Security (1977) The Composition of Mature Human Milk. Report of the Working Party on the Composition of Foods for Infants and Young Children. Report on Health and Social Subjects no. 12. London: HMSO.

18. Conn JA, Davies MJ, Walker RB et al. (2009) Food and nutrient intakes of 9-month-old infants in Adelaide, Australia. Public Health Nutr 12, 2448-2456.

19. Wells JC \& Davies PS (1998) Estimation of the energy cost of physical activity in infancy. Arch Dis Child 78, 131-136.

20. Wells JC \& Davies PS (1999) Can body size predict infant energy requirements? Arch Dis Child 81, 429-430. 
21. Nordic Council of Ministers (2004) Nordic Nutrition Recommendations 2004. Integrating Nutrition and Physical Activity. Copenhagen: Nordic Council of Ministers.

22. Alexy U, Kersting M, Sichert-Hellert W et al. (1999) Macronutrient intake of 3- to 36-month-old German infants and children: results of the DONALD Study. Dortmund Nutritional and Anthropometric Longitudinally Designed Study. Ann Nutr Metab 43, 14-22.

23. Koletzko B (1999) Response to and range of acceptable fat intakes in infants and children. Eur J Clin Nutr 53, Suppl. 1, S78-S83.

24. National Board of Health (Denmark) (2005) Recommendations for the Nutrition of Infants, Recommendations for Health Personnel (in Danish). Copenhagen: National Board of Health.
25. American Academy of Pediatrics, Committee on Nutrition (1992) The use of whole cow's milk in infancy. Pediatrics 89, 1105-1109.

26. Department of Health (1994) Weaning and the Weaning Diet. Report on Health and Social Subjects no. 45. London: HMSO.

27. Schiess S, Grote V, Scaglioni S et al. (2010) Introduction of complementary feeding in 5 European countries. J Pediatr Gastroenterol Nutr 50, 92-98.

28. World Health Organization (2001) The Optimal Duration of Exclusive Breastfeeding. Report of an Expert Consultation WHO/FCH/CAH/01.24. Geneva: WHO.

29. Agostoni C, Braegger C, Decsi T et al. (2009) Breastfeeding: a commentary by the ESPGHAN Committee on Nutrition. J Pediatr Gastroenterol Nutr 49, 112-125. 